\title{
Does demographic entrapment challenge the two-child paradigm?
}

\author{
MAURICE KING,' CHARLES ELLIOTT,${ }^{2}$ HAKAN HELLBERG, ${ }^{3}$ RICHARD LILFORD, \\ JEAN MARTIN, ${ }^{2}$ EDWIN ROCK, 5 JASON MWENDA 6 \\ IInstitute of Epidemiology and Health Services Research, University of Leeds, UK, 'Trinity Hall, \\ Cambridge, UK, "The Finnish Red Cross, Helsinki, 'Service de Sante Publique, Lausanne, \\ Switzerland, ${ }^{5}$ Stanford University School of Medicine, USA, and ${ }^{5}$ Institute of Primate Research, \\ National Museums of Kenya
}

\begin{abstract}
Local demographic entrapment has been discussed informally for many years, but is taboo to the UN agencies and to much of academia. There are also indications that the world as a whole may be demographically trapped in that global per capita grain production is falling. Arguments for and against recognizing entrapment are discussed. Policy implications of entrapment are outlined in the light of the 1994 International Conference on Population and Development (ICPD). The case for a one-child world is argued. Carrying capacity, disentrapment, the two-child paradigm, abortion, Rwanda and North/South tensions are considered.
\end{abstract}

\section{Background}

Policies in any field are largely set by 'the current paradigm' - the generally accepted view at the time. In international public health and family planning, this view is that, if all the unmet need for family planning is eventually met, and a twochild norm ultimately achieved, this will be demographically sufficient, and no account need be taken of carrying capacity limitations or of entrapment meanwhile. This paradigm is so allpervading, and any alternatives to it are so unperceived that it does not even seem to need a name, in that the term 'two-child paradigm' is not to be found in the POPLINE database. There was not a hint of any departure from it at the Conference on Population and Development (ICPD) in Cairo in 1994. Has the time come to question it locally and globally?

A notable feature of medicine since the 1950s has been the rise and fall of a succession of programmes like 'waves on the public health ocean'. Which waves are now missing or are seriously weak? What force could drive them, and what policies should follow from them? Two programmes now need to be tidal waves driven by an earthquake. They are those for the control of population in the South, and for a sustainable lifestyle in the North. The average Northerner currently lives at the rate of $7.5 \mathrm{kw}$ of mostly fossil energy for all purposes, 50 times more than in the South, ${ }^{1}$ and by converting it to carbon dioxide contributes disproportionately to the greenhouse effect that already appears to be changing the climate of the world. Equity, the welfare of mankind, and the stewardship of the earth require that these programmes be linked.

There is much good population news. Fertility has fallen rapidly in parts of Asia and Latin America and spectacularly in China and Indonesia. It can fall without much socioeconomic development, as in Bangladesh. There are even the possible beginnings of a demographic transition in parts of sub-Saharan Africa. ${ }^{2}$ There has been a slowdown in the rate of increase of world population from $2.1 \%$ in 1970 to $1.8 \%$ in 1977 . The bad news is that the rate of increase has virtually plateaued since 1980 , in that it only fell $0.1 \%$ in the 16 years to 1993 . Moreover, the annual increment, presently about 94 million people a year, is still rising, and will persist at more than 80 million people annually until at least 2025, with the result that the world's 
population is projected to reach $10-11$ billion (UN medium variant) at the end of the next century. ${ }^{3}$

\section{Can 11 billion people be fed?}

No phase in human history lasts indefinitely. This is likely to include the phase of massive increase in food production that has resulted from the application of science to agriculture. We cannot rely on an unlimited series of advances of the magnitude of the Haber-Bosch process for fixing nitrogen, which is now responsible for a third of all the protein-nitrogen we eat. ${ }^{4}$ The flow of new yield-raising agricultural technologies has not run dry, but it has slowed to a trickle. ${ }^{5}$ There are no new technologies in prospect which suggest that farmers can restore the $3 \%$ increase in global grain production that took place annually from 1950 to $1984 .^{5}$ Water is a greater constraint than arable land per capita, which is falling $1.9 \%$ annually. The response of crops to additional fertiliser and its global use are also falling. ${ }^{5}$ Half a billion people are already farming on hill-sides that are subject to serious erosion. ${ }^{6}$ By the end of this decade more than half of the developing countries may be unable to feed themselves from their own lands. ${ }^{7}$

There must be some upper limit to the food that the world can produce. If so the curve for the food it produces must initially be sigmoid (this does not preclude the possibility of a subsequent fall). In deciding where the upper limit might be we should remind ourselves that we shall have to eat what the world will produce, with all our shortcomings and the limited advances of science, not what it could produce without our failings, and supported by an unlimited series of scientific breakthroughs. The trend of the curve for global food is therefore critical, and particularly any signs of a fall-off in its rate of increase, indicating that we are reaching the upper inflection of the sigma.

So how can global food be measured? There are three imperfect and sometimes conflicting indices:

(1) FAO's index of food production. This was used by $\mathrm{UNFPA}^{3}$ to reassure the Cairo conference that '. . . During the past 10 years the world's food production has increased by $24 \%$, outpacing the rate of population growth ...'8 (about 18\%). For a base year this index takes the volumes of all foods produced (excluding seed, animal feed, and non-nutrients such as coffee), multiplies these by their local prices, and obtains a product in terms of money. It then takes the volumes of the foods produced in a subsequent year, multiplies these volumes by the prices in the base year (to correct for inflation), and compares this product, as a percentage, with the product obtained for the base year. The result of aggregating all the money spent on food and seeing how this changes over time is that the more expensive foods eaten by the rich get disproportionate weighting, compared to the cheap staples that feed the poor. The money spent on them also increases disproportionately as the rich get richer. This index becomes less reliable as the subsequent year and the base year become further apart, and has little validity after 10 years, so it cannot be reliably plotted continuously.

(2) Dietary energy supply for all foods (DES). This aggregates all calories consumed and is more meaningful, but is not available on a global basis.

(3) Total grain produced globally. Grain supplies about half the world's dietary energy, is particularly the food of the poor, and is much the most practical way in which food can be stored and transported, especially as food aid. Grain is thus the most practical indicator; several other basic foods follow similar or less favourable per capita trends (seafood, beef, mutton, etc.). ${ }^{3}$ Although root crops, particularly cassava, are important in many areas, and have done much to increase carrying capacity and tide communities through famines, they cannot easily be transported round the world, or stored many months in a silo.

Global grain production is therefore critical. The key question is: Have we already reached the upper inflection of the sigmoid global grain curve? If total grain shows signs of plateauing, but population does not, per capita grain will start falling. Is this already happening? Brown (1994) reports that per capita grain has indeed fallen $12 \%$ since 1984 , and finds that over the last 10 years the average annual increment in global grain has been 12 million tonnes.' At Chinese levels (three people to the tonne) this only feeds 36 million additional people. FAO (1994) also 
confirms a recent per capita fall, but finds the 10-year annual increment to have been 22 million tonnes (food for 66 million people). ${ }^{9}$ Even the most hopeful interpretation of existing trends is far from encouraging: 'The production data for the last two years are preliminary, but if they turn out to be correct, and if grain production continues to fall below that of the early $1990 \mathrm{~s}$, then we shall soon be on a statistically significant downward trend of grain production per person'. ${ }^{10}$

Although the recent fall in global per capita grain production is generally accepted, its significance is disputed, " since it may be due to the fall in grain price resulting from common market agricultural policies, which may have reduced the area under grain elsewhere, particularly setaside land in North America. There is also the possible switch of land from grain to other crops. We argue that if setaside land, which is generally marginal, had to be used to reach the 1984 maximum in per capita grain, this is as significant for long-term global food security as falling per capita grain would be without setaside. The medium term outlook is not reassuring. In 1990 the world grew 1.9 Mt of grain. By 2020 , only half a lifetime away, it is expected to need 2.9 $\mathrm{Mt}$, or half as much again. ${ }^{11}$ It is expected that '. . food demands for the next 30 years will mostly [our italics] be met . . '"ll which is also to expect that they will partly not be met. Nobody knows how large the shortfall could be. What the long-term sustainability of grain production might be is even less certain. A major risk is that due to the increasing variability of grain production in North America, it may experience two bad years in succession. If Africa, where harvests are also becoming increasingly variable, also has a bad year, the situation could be serious.

Since people must eat, the curve for global population must be sigmoid also, but it need not follow that for grain exactly, because grain consumption can vary by a factor of four, and ranges from $200 \mathrm{~kg}$ annually in India, to $800 \mathrm{~kg}$ in the United States where much grain is fed to animals first. ${ }^{5}$ Distribution is therefore critical. Although enough calories and protein are already produced to feed 10 billion people on a vegetarian diet, 12 '. . . it seems unlikely that those who can eat meat will forgo the opportunity to do so; instead they will be joined by hundreds of millions who will be able to act on their preference for meat in their diet . . .'13 The prospects for redistributing food by a global shift towards a vegetarian diet do not seem good. To those who argue that there is 'slack in the food system'4 in the same sense that there was the slack in the energy system prior to the oil price rise of the 1970 s, we point out that, unlike the energy system where it was in the interests of all users to economize, the slack is mostly in the rich part of the food system whereas the hungry are in the poor part. There is thus less incentive to take up and distribute the slack.

If falling per capita grain really does imply a deteriorating global food situation, every extra person now means less food for someone else, yet world population is set to double, and about a fifth of the people in the developing world were already chronically undernourished in 1990. ${ }^{14}$ The magnitude of the shortfall is not easily comprehended - population growth is now such that to feed every day's increment requires an additional 80000 tonnes of grain a year, continued indefinitely. Of each new conception we now need to ask: How likely is it that the earth will produce the 25 tonnes of grain that this new life is going to need?

The fact that grain prices have fallen in real terms over the last decade should be no cause for complacency, sinced the hungry poor cannot pay more for their grain, nor can they sustain the price rise that might increase output. Yet without such a price rise, peasant farmers, as in Zambia at the present time, cannot afford the fertilizer and other inputs that might increase production. Will the rich be prepared to subsidize the necessary agricultural inputs and be willing to pay more for the grain they supply as food aid? Where are sub-Saharan Africa and Bangladesh to get the foreign exchange they will need to import grain which seems likely to become increasingly expensive?

\section{The plight of particular communities}

Whatever may be the prospects for the world as a whole, the prospects for some individual communities are dire. For many years aid agency executives have been referring informally to a 
condition termed 'demographic entrapment'. This condition has recently been defined. ${ }^{15}$ Here is that definition slightly modified by recent events in Rwanda.

A local population is demographically trapped if it has exceeded, or is projected to exceed the combination of: (a) the carrying capacity of its own ecosystem, (b) its ability to obtain the products, and particularly the food, produced by other ecosystems except as food aid, and (c) its ability to migrate to other ecosystems in a manner which preserves (or improves) its standard of living (upmigration). Items (b) and (c) describe the links that a population has with other ecosystems, and are crucial, so they are most easily thought of as 'connectedness' and its opposite 'disconnectedness'.

A severely trapped population faces the five alternatives of entrapment in varying combination. Depending on local cultural, political and ecological factors it can: (1) become progressively stunted, and/or starve; (2) die from disease; (3) slaughter itself or its neighbours; (4) migrate in misery to a refugee camp or urban slum (downmigration); (5) be supported indefinitely by food aid (if food is available). Whether a population stunts and starves, or if and when slaughter breaks out, is likely to depend on whether there are severe ethnic or political rifts in the population already, as particularly in Rwanda.

Since endangered populations are growing rapidly, the critical part of the definition is '. . . is projected to ... ', and concerns the ultimate size of a population at the end of its demographic transition when its demographic momentum is exhausted, in relation to its carrying capacity and its connectedness. The major constraint is time, and particularly whether such measures as female education, etc. have time to bring the birth rate down before carrying capacity and connectedness are exceeded. UNICEF's PPE spiral (poverty, population, environment) describes an important part of the entrapment process, but does not go far enough, in that UNICEF does not recognise entrapment or its ending in the tragedy of 'the five alternatives', nor does UNICEF accept the rigour of the steps that are needed to prevent them.
Do communities defined as trapped by this definition, actually exist? Before the recent tragedy in Rwanda it was easier to argue that they did not. Rwanda was already high on the list of the presumably trapped countries ${ }^{15}$ before the present tragedy. Some observers had been expecting disaster there any day. $R$ wanda is one of the most densely populated countries in Africa, and has the highest total fertility in the world, 8.5 children per woman. Population pressure is intense with many families on only half a hectare and much malnutrition. In the 1970 s its carrying capacity was estimated to be 6-7 million. In 1994, when its population had reached 7.6 million, the genocide endemic in the region suddenly escalated by an order of magnitude. Although the human rights movement has argued that population pressure is a myth in $\mathrm{R}$ wanda, we argue that it has many links with factors that exacerbate genocide, both in the phase in which genocide is planned, and in the phase in which it runs wild in the community. Once violence begins in an intensely trapped community, there is a considerable temptation to slaughter your neighbour, and seize his half hectare before he does the same to you.

Rwanda is bad enough, but how many countries are due to follow it? No formal study of entrapment has yet been done, so great is the reluctance to do such a study, to fund it, or to host it, since it amounts in effect to a diagnosis of which communities are going to face the five alternatives of entrapment, and when might this happen? There is however wide informal agreement that parts of the Indian subcontinent and much of subSaharan Africa are demographically trapped. ${ }^{15}$

If this is local demographic entrapment, what then might be global entrapment? Unlike a local community, the world as a whole is a closed system, with no extraterrestrial migration, no exports, no imports except the sun's photons, and no possibility of food aid. As a definition we suggest that: 'The world's population is demographically trapped if it has exceeded or is projected to exceed the carrying capacity of the earth, as shown by a falling per capita grain consumption.' This has the virtue of matching the definition of local entrapment and being based on per capita grain consumption, the most solid indicator. 


\section{Should (local) entrapment be recognized?}

Only once has entrapment ever been officially mentioned by any UN agency. ${ }^{16}$ It is also taboo in much of academia. Whether it should be recognized or not is the major policy decision in international health at the present time. There are powerful arguments for and against recognizing it.

\section{The arguments for recognizing entrapment}

- The need to seek and face the truth, North and South - this is the compelling argument. The longer we postpone doing this, the more difficult will it eventually become.

- There is much we can do.

- We should face the subsidiary dilemmas actively rather than by default, particularly the conflict between the interests of the foetus (and the child ${ }^{15}$ ) in a severely trapped community, and those of the community itself. For children this dilemma is only significant if child mortality is high. It mainly concerns programme priorities, and the disposition of new resources.

- We should not keep trapped communities in ignorance of their plight.

- At the very least the recognition of entrapment would give a powerful boost to ordinary family planning (down to a two-child norm).

- Some communities might accept one-child families. The world has in effect a number of other 'Chinas', in that they are in the same position demographically as China was when it instituted its one-child families, but they don't recognize their predicament. From a global perspective, we argue that every community must do so (see below).

\section{The arguments against recognizing entrapment}

- The trapped poor might be unduly coerced to restrict their fertility by their own elites. One of the major weaknesses of the two-child paradigm is that it takes human rights as an absolute 'given', and denies that the ecological constraints upon humans of population, territory and food, etc. influence these rights in any way. The reality is that our rights and ethics have to fit in with ecology, since it will not fit in with us. It is not that we don't have any rights, but that such rights as we do have must take ecology as a 'given', and not vice versa - as at present. Which coercions are justified? There are some practices (torture, for example) which must be considered ethically unacceptable in all societies. There are, however, other practices (incentives and penalties relating to abortion), which may be justified in a trapped community faced with the dilemma of aborted foetuses or starving adults, but which are not justified in a non-trapped one which does not face this dilemma. Just which incentives and which penalties are justified in a trapped community in the support of abortion now needs urgent discussion. We should be cautious in critizing the ethics of a trapped community from the perspective of a non-trapped one.

- We cannot forecast the future. There is nothing we can do, in that we are powerless to alter the development dynamic in the South, or to adequately assist it to control its fertility, nor can we reduce resource consumption and pollution by the North (in effect fatalism).

- To admit the existence of entrapment is to break a taboo. Unfortunately, taboos may be necessary for the stability of a society in ways which may not always be immediately apparent. Here the taboo seems necessary for relieving our anxiety, for preserving our comforting shortterm view of the world, for the present relative stability of North-South relations, and for maintaining the current paradigm in public health.

- Finally, there are the tensions that could be liberated by discussing entrapment.

Two issues are particularly important for policy:

Should communitles be faced with the dilemma: If you don't radically limit your fertility, if necessary to one child, you can expect to starve? President Chiluba of Zambia was recently asked about the size of his family. He replied: 'I am just like any African, I have nine children.' 17 In neighbouring Malawi, where $56 \%$ of the farms already have a mean size of only 0.55 hectare, total fertility is 7.6. ${ }^{18}$ The World Bank estimates that, if current food production and growth trends continue, ${ }^{19}$ the food shortage for Africa will amount to 250 million tonnes of grain by 2020 , or 20 times its current food gap. This is more than all the grain currently traded on the international market (about 200 million tonnes). 
Hopefully, present trends will not continue. ${ }^{20}$ Since they might, the questions which now have to be asked are: 'Should, and can, the rest of the world guarantee to feed Africa indefinitely if its present fertility pattern continues?' Has the time come to face presidents and communities with the situation: If you don't reduce your fertility radically, if necessary to one-child, you may be faced with the five alternatives of entrapment? We think it has. Urgent studies of carrying capacity and entrapment are required. They are likely to be disturbing and to present local decision-makers with the dilemma: should policies and plans be set by what should happen in a perfectly equitable world, or by what will probably happen in our present inequitable one? Hopefully, there will be some shift towards equity, but probably not enough.

\section{Are the tensions that might be liberated by the} discussion of entrapment to be welcomed?

The tensions liberated by discussing "Who is going to starve while we have plenty to eat?' might be severe. If entrapment is recognized, powerful forces could be released, with no telling what the end result might be. However, these forces appear to be the only ones that might possibly produce the earthquake that the world requires, as the ideological tectonic plates that support North and South grind and shudder against one another to propel the necessary tidal waves in our lifestyle and our reproduction. The hope must be that the energies so liberated can be channelled constructively to produce the changes that the world so badly needs. The danger is that they might be destructive. Persisting with the status quo is however likely to be worse, with more ecological destruction, more global warming, and more strife and starvation. Paradoxically therefore, the release of these tensions, if indeed they can be released, is an excellent reason for recognizing entrapment.

How violent these tensions will actually be remains to be seen. They might be weaker than expected, since the world appears to be moving from a North/South polarity towards a rich/ poor one, in which Southern elites who are not trapped, since they are able to migrate whereas the poor cannot, side with the North. Because the trapped poor are powerless, and are not present at international meetings, the release of tensions may be moderated. Thus Nafis Sadik,
Executive Director of UNFPA, who is from Pakistan which is presumptively trapped, and who is well aware of entrapment, chose not to discuss it in Cairo. Of 43 Zambian postgraduates, mostly $\mathrm{PhDs}$, recently interviewed in Cambridge, none intended returning to Zambia. Instead of the creative furore of North grinding against South, there may instead be a silent squelch as the rich slide over the poor.

Vigorous or not, we welcome the release of the tensions that the recognition of entrapment might produce, as being the only forces which might possibly induce the North to reduce its resource consumption and pollution, and the South its fertility. These changes are linked, in that neither the North nor the South can do what the other must do. Much depends on the rationality of both North and South, and what sense of equity, if any, there is in the North.

\section{A missed opportunity - the 'Declaration of Cairo for a one-child world'}

Adherence to the two-child paradigm was unquestioned in Cairo. Privately however, many aid agency executives and academics have no illusions about its weakness. The result is an increasing degree of doublethink ${ }^{15}$ as official and unofficial views of reality drift progressively further apart.

If, following Brown, the current annual grain increment really is only 12 million tonnes of grain, feeding 36 million people, this calls for a onechild world - if per capita grain is not to continue to fall. A two-child world would produce an annual increment of 50 million people between now and 2030. ${ }^{21}$ FAO's estimate of a 22 million tonne annual increment would, however, feed 66 million people and suffice for an instant twochild world. Estimates of the current per capita grain increment, the reasons for its fall, and projections of what it will do in future, are so varied that it would be politically impracticable for a global one-child policy to be based on this data alone. Nevertheless, in the face of any uncertainty over future global grain and its redistribution, it is better to be safe than sorry. The most powerful argument for a one-child world is, however, that, if local communities need onechild families to avoid starvation or the other alternatives of entrapment, the rest of the world 
should, in the interests of equity do the same, particularly since the average British family, for example, consumes resources and pollutes at a rate equivalent to $15-25$ average global families. ${ }^{22}$ If other communities opt independently for one-child families, as did China, that is their decision, but if we counsel communities to have one-child families, we must in the interests of equity, also have them ourselves, or drastically cut our consumption of nonrenewable resources.

Some of us have argued ${ }^{23}$ that the ICPD should have produced a 'Declaration of Cairo for a onechild world' - less as a specific target than what WHO's previous director general, Halfdan Mahler, would have called 'a political direction' in the manner of 'Primary Health Care', or 'Health for all for the World 2000'. It seems likely that history will consider this to have been a lost opportunity.

In the event, the programme for Cairo was set at preparatory conferences long before. These followed the current two-child paradigm and took no account of either global food uncertainties, or demographic entrapment. 'A one-child world' is likely to be an even more urgent policy option for the next ICPD in 2004. Will the prevailing paradigm have changed meanwhile? There are early signs that it is already starting to do so. Such however is the inertia of opinions, policies and plans, that this will take some years. Meanwhile, the global population increases at 10000 an hour, or more than two billion over the next two decades, and, for whatever reason, per capita grain is presently falling. ${ }^{5,9}$

If this paper is considered pessimistic, let it be remembered that we have proposed, hopeful, courageous, and far-reaching policies. Their attainment depends on whether we really want these changes, or whether we would actually prefer the status quo. We suggest that there may be a case for opening up the dialogue on the faults in the two-child paradigm, no matter how firmly entrenched it appears to be.

\section{References}

1 Ehrlich PR, Ehrlich AH. Healing the planet. Addison Wesley. Reading, Massachusetts. 1991, p41.

2 UNICEF. State of the World's Children 1994. New York.
3 UNFPA. State of the World Population 1994. New York.

4 Smil V. How many people can the Earth feed? Population and Development Review 1994; 20; 255-92.

3 Brown L. State of the World 1994. The Worldwatch Institute. 1994. New York: WW Norton.

6 World Food Council. Sustainable food security: action for environmental management of agriculture. WFC/1988/5/add.1, WFC, Rome 1988.

7 Population Reports. Series M Number 10, pl, May 1992. Population Information Program, Centre for Communication Programs, The Johns Hopkins School of Hygiene and Public Health, Baltimore.

${ }^{8}$ World Resources Institute 1992-1993 report, page 271, quoting FAO Agrostat PC, Rome 1991.

9 Food outlook 5/6, FAO 1994. FAO, Rome.

10 Pinstrup-Andersen PA. World food trends and how they might be modified. Paper prepared for CGIAR International Centres Week. International Food Policy Research Institute (IFPRI), Washington DC. 1993.

11 Dyson T. World population growth and food supplies. International Sacial Science Journal 1994; 141: 361-85.

12 Waggoner, Paul E. 'How much land can ten billion people spare for nature?' Task Force Report No. 121, 1994. Council for Agricultural Science and Technology. Ames, Iowa.

13 Preston S. Population and Environment. IUSSP Distinguished Lecture Series on Population and Development. Cairo 1994.

14 FAO:WHO. Nutrition and Development: A global assessment. Rome: Food and Agriculture Organisation of the United Nations. 1992.

15 King MH, Elliott C. Legitimate Double Think. Lancet 1993; 341: 669-72.

16 WHO. Reflections at the midpoint; From Alma Ata to the Year 2000. Alma Ata revisited. The Riga conference, 1990.

17 . Watts R. The Manchester Guardian Weekly September 15 th, 1994; p2.

18 Situation Analysis of Poverty in Malawi. UN Malawi, 1993.

19 World Bank. Sub-Saharan Africa: From Crisis to Sustainable Growth. New York. 1989.

20 Dyson, in preparation.

21 Calculation by Richard Leete.

22 Myers N. Population, Environment and Development. Mimeo. Prepared for the Royal Society of London for the New Delhi Population Conference in October 1993.

23 King MH, Elliott C, Hellberg H, Lilford R, Martin J, Rock E. A one-child world. Paper circulated at the International Conference on Population and Development, Cairo 1994.

\section{Biographies}

Maurice King is a Research Fellow at the Institute of Epidemiology and Health Services Research, University of Leeds, and is presently working from Geneva. He spent 20 years in Africa and is the author of 10 books on the health problems of the developing world.

Charles Elliott is Dean and Chaplain of Trinity Hall Cambridge, a development economist, and former Director of Christian Aid. 
Hakån Hellberg has been Director of the Finnish Red Cross, a Staff member with WHO, and a missionary doctor in Namibia.

Richard Lilford is Professor of Obstetrics and Gynaecology and Chairman of the Institute of Epidemiology and Health Services Research, The University of Leeds.

Jean Martin is Chief Cantonal Medical Officer, Public Health Service of the Canton of Vaud, and Lecturer in Preventive and Social Medicine at the University of
Lausanne, Switzerland. Earlier he spent 8 years overseas in the international health field.

Edwin Rock is in the Department of Microbiology and Immunology at the Stanford University School of Medicine supported by a grant from the Charles $A$ Lindbergh fund.

Jason Mwenda is Senior Research Scientist, Institute of Primate Research, National Museums of Kenya.

Correspondence: Dr Maurice King, I bis Rue du Tir, Geneva 1204, Switzerland. 